\title{
The role of surgeon volume on patient outcome in total knee arthroplasty: a systematic review of the literature
}

\author{
Rick L Lau ${ }^{1 *}$, Anthony V Perruccio ${ }^{2}$, Rajiv Gandhi ${ }^{3}$ and Nizar N Mahomed ${ }^{3}$
}

\begin{abstract}
Background: A number of factors have been identified as influencing total knee arthroplasty outcomes, including patient factors such as gender and medical comorbidity, technical factors such as alignment of the prosthesis, and provider factors such as hospital and surgeon procedure volumes. Recently, strategies aimed at optimizing provider factors have been proposed, including regionalization of total joint arthroplasty to higher volume centers, and adoption of volume standards. To contribute to the discussions concerning the optimization of provider factors and proposals to regionalize total knee arthroplasty practices, we undertook a systematic review to investigate the association between surgeon volume and primary total knee arthroplasty outcomes.

Methods: We performed a systematic review examining the association between surgeon volume and primary knee arthroplasty outcomes. To be included in the review, the study population had to include patients undergoing primary total knee arthroplasty. Studies had to report on the association between surgeon volume and primary total knee arthroplasty outcomes, including perioperative mortality and morbidity, patient-reported outcomes, or total knee arthroplasty implant survivorship. There were no restrictions placed on study design or language.
\end{abstract}

Results: Studies were variable in defining surgeon volume ('low': $<3$ to $<52$ total knee arthroplasty per year; 'high': $>5$ to $>70$ total knee arthroplasty per year). Mortality rate, survivorship and thromboembolic events were not found to be associated with surgeon volume. We found a significant association between low surgeon volume and higher rate of infection ( $0.26 \%-2.8 \%$ higher), procedure time (165 min versus $135 \mathrm{~min})$, longer length of stay ( $0.4-2.13$ days longer), transfusion rate (13\% versus 4\%), and worse patient reported outcomes.

Conclusions: Findings suggest a trend towards better outcomes for higher volume surgeons, but results must be interpreted with caution.

Keywords: Surgeon volume, Knee arthroplasty

\section{Background}

Primary total knee arthroplasty (TKA) is recognized as an effective treatment for alleviating the pain and disability associated with end stage knee osteoarthritis $[1,2]$. Despite the widespread success of primary TKA, a significant minority of patients (ranging from 10-20\%) continue to experience complications and report poor outcomes following this procedure $[2,3]$. The

\footnotetext{
* Correspondence: rick.lau3@gmail.com

'Division of Orthopaedics, Department of Surgery Kingston General Hospital, Queen's University, 76 Stuart St., Nickle 3, Rm 9-309, Kingston, ON K7L 2V7, Canada

Full list of author information is available at the end of the article
}

implications are significant considering that the total number of primary TKA procedures is expected to increase by over $600 \%$ in the United States alone, to nearly 3.5 million procedures over the next 20 years [4].

A number of factors have been identified as influencing TKA outcomes, including patient factors such as gender and medical comorbidity [5,6], technical factors such as alignment of the prosthesis [7], and provider factors such as hospital and surgeon procedure volumes [8-10]. Recently, strategies aimed at optimizing provider factors have been proposed, including regionalization of total

\section{Biomed Central}

(C) 2012 Lau et al.; licensee BioMed Central Ltd. This is an Open Access article distributed under the terms of the Creative Commons Attribution License (http://creativecommons.org/licenses/by/2.0), which permits unrestricted use, distribution, and reproduction in any medium, provided the original work is properly cited. 
joint arthroplasty to higher volume centers, and adoption of volume standards $[8,10,11]$.

Higher hospital procedure volumes have been associated with improved outcomes across a variety of cardiac, vascular and oncologic surgeries [12-14]. Several studies have examined the influence of hospital volume on TKA outcomes as well [10,15-17]. Higher hospital volumes have been shown to be negatively associated with mortality rates and positively associated with implant survivorship following TKA [18]. However, the association between surgeon volume and TKA outcomes is unclear. Over the past two decades a number of studies have examined the influence of surgeon volume on various TKA outcomes. However, there has not been a systematic review which has focused exclusively on surgeon volume and primary TKA outcomes. To contribute to the discussions concerning the optimization of provider factors and proposals to regionalize TKA practices, we undertook a systematic review to investigate the association between surgeon volume and primary TKA outcomes.

\section{Methods \\ Eligibility criteria}

To be included in the review, the study population had to include patients undergoing primary TKA. Eligible studies had to compare primary TKA outcomes between low volume surgeons and high volume surgeons. Primary TKA outcomes including perioperative mortality and morbidity, patient-reported outcomes, or TKA implant survivorship were examined. Relevant papers were reviewed using the Preferred Reporting Items for Systematic reviews and Meta Analyses (PRISMA) statement as a guideline [19].

\section{Information sources and study selection}

We searched the Pubmed, OVID MEDLINE (1966 to 2011), and EMBASE (1974-2011) databases in October 2012 using the following search criteria: (knee arthroplasty OR knee replacement) AND (surgeon volume OR surgeon experience). No restrictions were placed on publication date, study design or language. Following these initial searches, we performed a second electronic search using the following terms: arthroplasty and volume, joint replacement and volume to further the breadth of our search. Two authors screened all titles and abstracts retrieved from this search (RLL, RG). Fulllength articles were retrieved for all articles that were considered either potentially relevant or where there was uncertainty as to the relevance. Additionally, the bibliographies of these full-length articles were reviewed and full length articles retrieved for those references deemed potentially relevant or of uncertain relevance. Full-length articles were reviewed by two reviewers (RLL,RG) and data was independently extracted. When manuscripts included data on TKA and total hip arthroplasty (THA), or primary TKA and revision TKA, they were excluded unless the primary TKA data were reported separately. Similarly, when manuscripts included data on hospital and surgeon volume they were excluded unless the surgeon volume data was reported separate from hospital volume data.

\section{Data extraction}

The following study characteristics were documented: study design, date, data source, sample size, characterization of surgeon volume, and examined primary TKA outcome(s).

\section{Quality appraisal of studies}

The studies that were included in our review underwent an appraisal of the quality of methodology as outlined by the Grading of Recommendations Assessment, Development and Evaluation (GRADE) system [20].

\section{Results}

Study selection

We identified 144 abstracts using our initial electronic search for screening. Secondary electronic searches identified 824 and 949 abstracts for screening. After title and abstracts were screened, 18 met inclusion criteria and the full-length articles were retrieved and reviewed [8-10,18,21-34]. Hand searches of the bibliographies of these 18 articles resulted in the inclusion of 13 more articles [11,15-17,35-43], for a total of 31. Following the full-length reviews, 20 articles were excluded. Sixteen were excluded because they did not compare low volume surgeons to high volume surgeons [11,15$17,29,33,35-44]$, two studies were excluded because TKA data was mixed with THA data [23,34], one study was excluded because primary TKA data was reported with revision TKA data [10], and one study was found to be a review article and thus, not eligible for inclusion [24]. Eleven studies met our inclusion/exclusion criteria and were retained for this review $[8,9,18,21,22,25$ 28,30,32] (Figure 1).

\section{Study characteristics Study design}

All included studies were non-randomized, comparative (low vs. high surgeon volume) observational trials. Nine of the 11 studies were retrospective, and 2 were prospective (Table 1).

\section{Sample size}

Sample size (n) was recorded as number of patients. One study did not report the actual number of TKA procedures in their manuscript [28]. The remaining 


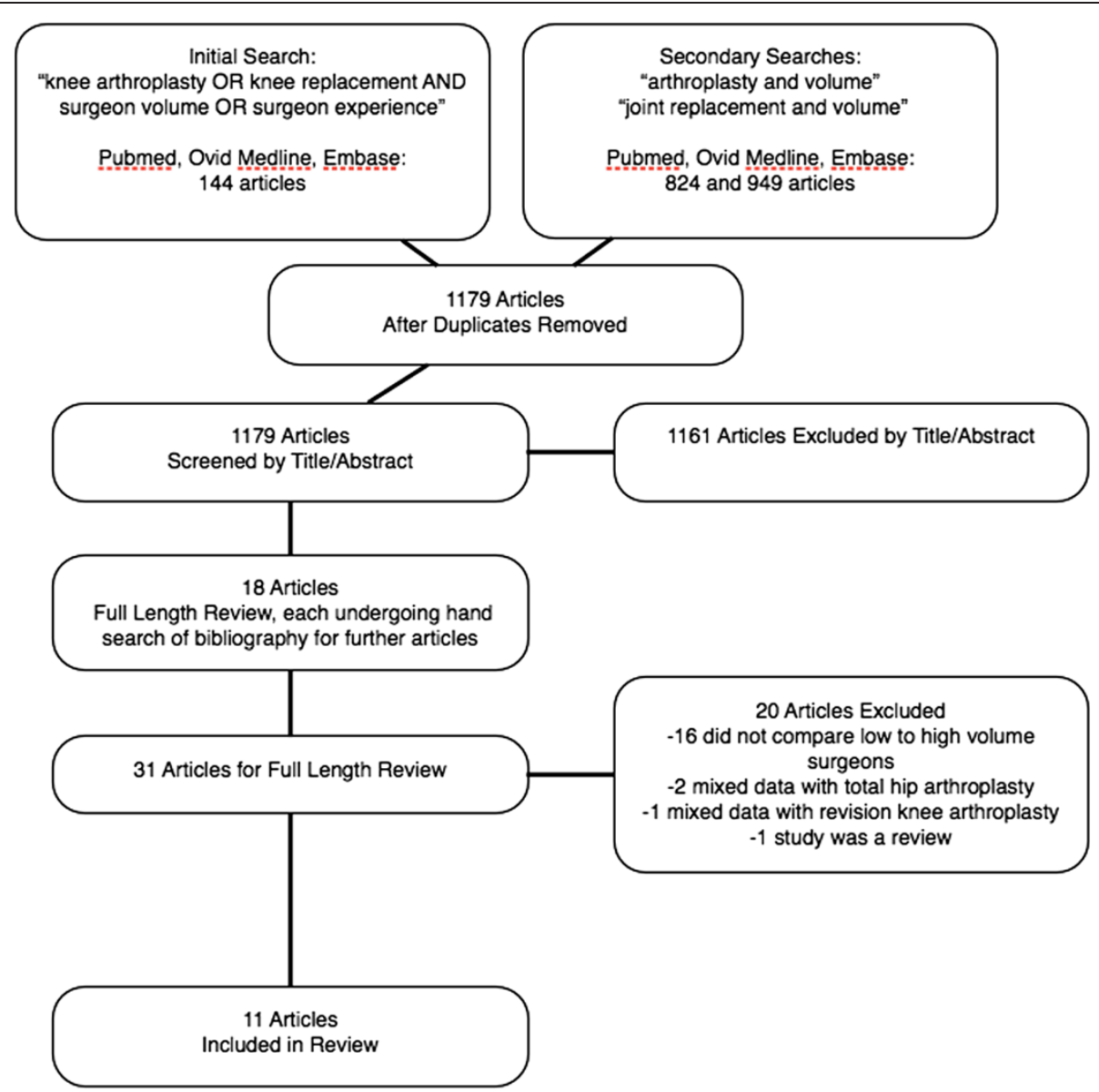

Figure 1 Selection of articles for review.

studies comprised 286875 patients. Across studies, sample size varied from a minimum of 260 to a maximum of 80904 (Table 1).

\section{Patient data source}

The majority of studies were North American based. Five studies were from the United States (US), 2 from Canada, 1 from United Kingdom, 1 from Japan, 1 from Taiwan, and 1 from the Netherlands.

The US studies made use of two databases to identify the patient cohorts. Four of the 5 studies utilized the US Medicare database $[8,9,18,28]$, and one used the Health Care Cost and Utilization Project Nationwide Inpatient Sample (HCUP-NIS) database [21]. The Medicare database contains claims data for services provided to beneficiaries (ages $\geq 65$ years and those with certain disabilities), including demographic, diagnostic and procedural data. The HCUP-NIS database was developed to help track and analyze trends in health care utilization, cost, quality and utilization and is collected on an annual basis from a nationwide sample of community hospitals in the US [10]. It contains information on all patient admissions at the participating hospitals with patient specific demographic and hospital data, as well as discharge information.

The Canadian studies utilized the Ontario Health Insurance Plan (OHIP) and Canadian Institute for Health Information (CIHI) databases [25,32]. OHIP is a government-run health insurance plan. Its database contains claims data for all physician billing (including patient, physician and hospital specific data) in the province of Ontario, Canada's most populous province. The CIHI maintains a national database of hospital admissions, and was used to supplement the OHIP data in the Kreder et al. and Paterson et al. studies [25,32].

The United Kingdom study utilized a local joint replacement database to identify patients, and used hospital records to collect data [22]. The national joint registry in United Kingdom was also used to collect demographic and procedure related data.

The Japanese study was derived from a nation-wide internet survey of orthopedic surgeons [27]. Surgeons provided patient information to survey questions from 
Table 1 Studies on surgeon volume and TKA outcome

\begin{tabular}{|c|c|c|c|c|c|c|}
\hline Study & $\begin{array}{l}\text { Patients } \\
\text { (n) }\end{array}$ & $\begin{array}{l}\text { Study } \\
\text { design }\end{array}$ & Country & $\begin{array}{l}\text { Year data } \\
\text { collected }\end{array}$ & Data source & Outcomes \\
\hline $\begin{array}{l}\text { Kreder et al } \\
(2003)\end{array}$ & 14352 & Retrospective & Canada & 1992-1996 & $\mathrm{OHIP}$ and $\mathrm{CIHI}$ & $\begin{array}{l}\text { MR (in hospital), MR (90d), infection, } \\
\text { revision, complication, LOS }\end{array}$ \\
\hline $\begin{array}{l}\text { Katz et al } \\
(2004)\end{array}$ & 80904 & Retrospective & US & 2000 & Medicare & MR (90d), MI, infection, pneumonia, PE \\
\hline $\begin{array}{l}\text { Katz et al } \\
(2007)\end{array}$ & 906 & Prospective & US & 2000 & Medicare, patient survey & $\begin{array}{l}\text { WOMAC, patient satisfaction, } 90 \text { degree } \\
\text { flexion, full extension }\end{array}$ \\
\hline $\begin{array}{l}\text { Muilwijk et al } \\
\text { (2007) }\end{array}$ & 6357 & Retrospective & Netherlands & 1996-2003 & $\begin{array}{l}\text { Dutch Nosocomial Infection } \\
\text { Surveillance Network }\end{array}$ & Infection \\
\hline $\begin{array}{l}\text { Manley et al } \\
(2009)\end{array}$ & 53971 & Retrospective & US & $1997-2004$ & Medicare & $2,5,8$ year implant survivorship \\
\hline $\begin{array}{l}\text { Ong et al } \\
\text { (2009) }\end{array}$ & NR & Retrospective & US & 1997-2004 & Medicare & Procedure duration \\
\hline $\begin{array}{l}\text { Yasunaga et } \\
\text { al (2009) }\end{array}$ & 3577 & Prospective & Japan & 2006-2007 & Web based surgeon survey & $\begin{array}{l}\text { MR (in-hospital), infection, DVT, PE, } \\
\text { pneumonia, LOS }\end{array}$ \\
\hline $\begin{array}{l}\text { Paterson et al } \\
(2010)\end{array}$ & 27217 & Retrospective & Canada & $2000-2004$ & $\mathrm{OHIP}$ and $\mathrm{ClHI}$ & $\begin{array}{l}\text { MR (90d), revision, readmission for surgery, } \\
\text { LOS, complications }\end{array}$ \\
\hline $\begin{array}{l}\text { Wei et al } \\
(2010)\end{array}$ & 31618 & Retrospective & Taiwan & $2000-2003$ & $\mathrm{NHI}$ & $\begin{array}{l}\text { LOS, hospital charges, infection, } \\
\text { complications }\end{array}$ \\
\hline $\begin{array}{l}\text { Styron et al } \\
(2011)\end{array}$ & 67713 & Retrospective & US & 2002 & HCUP database & LOS \\
\hline $\begin{array}{l}\text { Baker et al } \\
\text { (2011) }\end{array}$ & 260 & Retrospective & UK & 2006-2007 & $\begin{array}{l}\text { Local Database and National } \\
\text { Joint Registry }\end{array}$ & Transfusion rate \\
\hline
\end{tabular}

(MR Mortality rate, LOS Length of stay, HCUP Health Care Utilization Project, PE Pulmonary embolus, DVT Deep venous thrombosis, MI Myocardial infarction, WOMAC Western Ontario and McMaster Universities Osteoarthritis Index, OHIP Ontario Health Insurance Plan, CIHI Canadian Institute for Health Information, NHI National Health Insurance, NR Not reported).

patient's medical records. The data was then compiled into a database and results analyzed.

The Taiwanese study used the National Health Insurance (NHI) database [26]. The NHI stores data on $99 \%$ of the population in Taiwan, with patient specific clinical and demographic data collected since 1995.

The Dutch study used the surveillance network for nosocomial infections [Preventie Ziekenhuisinfecties door Surveillance Network database (PREZIES)] [30]. This database was designed in 1996, and collects data from participating hospitals on surgical site infections.

\section{Defining surgeon volume}

In classifying surgeon volume, 10 of the 11 studies used the annual number of procedures performed by the surgeon $[8,9,18,21,22,25,26,28,30,32]$, whereas one study utilized the career life-time number of procedures [27]. Significant variability was noted across studies in the manner in which surgeons were classified as high versus low volume. Thresholds were primarily based on tertiles or quartiles of the study-specific surgeon volume distributions. Five studies chose to use quartiles, and for these we labeled the surgeon volume categories as low, medium, high and very high $[8,18,21,25,28]$. Four studies chose to define surgeon volume based on tertiles; for these, we used the low, medium and high volume categories $[26,27,30,32]$. One study defined low volume surgeons as $<52$ procedures per year [22]. One study defined low volume surgeons as $<6$ procedures per year [9]. Due to the variability in categorization of surgeon volumes across studies, 'low' surgeon volumes ranged from $<3$ to $<52$ procedures per year across studies, and 'high' surgeon volume ranged from $>5$ to $>70$ procedures per year (Table 2).

\section{Examined outcomes}

Across studies, a variety of perioperative outcomes were reported (Table 1), including in-hospital mortality rate (MR) (2 of 11 studies) [27,32], 90 day MR (3 of 11 studies) $[8,25,32]$, pulmonary embolism (PE) (2 of 11 studies) [8,27], and deep venous thrombosis (DVT) (1 of 11 studies) [27]. Surgical site infections were reported in 5 of 11 studies $[8,26,27,30,32]$. Variable time frames were considered: in-hospital infections [26], 90-day post-operative period [8], 12-month post-operative period [30], and 3year post-operative period [32]. One study did not specify time point [27]. Two studies measured deep infections $[8,27]$, and 3 studies did not specify $[26,30,32]$.

Postoperative medical complications were reported in 6 of 11 studies [8,22,25-27,32]. Medical complications were defined differently in each study, and included myocardial infarction [8,25,26,32], pneumonia [8,25-27], cerebrovascular accident [25,32], anaesthetic complications 
Table 2 Surgeon volume thresholds and outcomes of the studies

\begin{tabular}{|c|c|c|c|c|c|c|c|c|}
\hline \multirow[t]{2}{*}{ Study } & \multicolumn{4}{|c|}{ Surgeon volume thresholds } & \multirow[t]{2}{*}{ Outcomes } & \multirow[t]{2}{*}{ Result } & \multirow{2}{*}{$\begin{array}{l}\text { LV vs. HV } \\
\text { surgeons }\end{array}$} & \multirow{2}{*}{$\begin{array}{l}\text { Adjusted odds ratios* } \\
(95 \% \mathrm{Cl})\end{array}$} \\
\hline & Low & Medium & High & V. High & & & & \\
\hline \multirow[t]{6}{*}{$\begin{array}{l}\text { Kreder et al } \\
(2003)\end{array}$} & $<14$ & $14-42$ & $>42$ & - & LOS & $\begin{array}{l}\mathrm{p}< \\
0.05\end{array}$ & 11.5 vs 10.0 days & NR \\
\hline & & & & & MR (in-hospital) & NS & $0.5 \%$ vs $0.3 \%$ & NR \\
\hline & & & & & MR (90 day) & NS & $0.8 \%$ vs $0.4 \%$ & $1.76(0.8-3.8)(\mathrm{LV}: \mathrm{HV})$ \\
\hline & & & & & Infection (3 yr) & NS & $2.1 \%$ vs $2.3 \%$ & $0.88(0.5-1.3)(\mathrm{LV}: \mathrm{HV})$ \\
\hline & & & & & Revision (3 yr) & NS & $2.2 \%$ vs $1.9 \%$ & $1.00(0.6-1.7)(\mathrm{LV}: \mathrm{HV})$ \\
\hline & & & & & Medical complication & NS & $9 \%$ vs $11 \%$ & $0.98(0.7-1.3)(\mathrm{LV}: \mathrm{HV})$ \\
\hline \multirow[t]{5}{*}{ Katz et al (2004) } & $1-12$ & $13-25$ & $26-50$ & $>50$ & Pneumonia & $\begin{array}{l}\mathrm{p}< \\
0.01 \#\end{array}$ & $1.68 \%$ vs $1.02 \%$ & $0.72(0.54-0.95)(H V: L V) \#$ \\
\hline & & & & & Infection & $\begin{array}{l}p< \\
0.01 \#\end{array}$ & $0.55 \%$ vs $0.29 \%$ & $0.62(0.37-1.06)(\mathrm{HV}: \mathrm{LV}) \#$ \\
\hline & & & & & $\mathrm{Ml}$ & NS & $0.8 \%$ vs $0.69 \%$ & $0.90(0.64-1.28)(\mathrm{HV}: \mathrm{LV})$ \\
\hline & & & & & PE & NS & $0.76 \%$ vs $0.74 \%$ & $1.06(0.73-1.54)(\mathrm{HV}: \mathrm{LV})$ \\
\hline & & & & & MR (90d) & NS & $0.67 \%$ vs $0.58 \%$ & $0.97(0.66-1.43)(\mathrm{HV}: \mathrm{LV})$ \\
\hline \multirow[t]{4}{*}{ Katz et al (2007) } & $1-6$ & & $>6$ & & $\begin{array}{l}\text { poor WOMAC score } \\
(\text { score }<60)\end{array}$ & $\begin{array}{l}\mathrm{p}< \\
0.05\end{array}$ & $22.6 \%$ vs $8.4 \%$ & 2.1 (1.1-4.2) (LV:HV) \\
\hline & & & & & flex to 90 degrees & $\begin{array}{l}\mathrm{p}< \\
0.05 \\
\end{array}$ & NR & 2.9 (1.6-5.5) (LV:HV) \\
\hline & & & & & full extension & $\begin{array}{l}\mathrm{p}< \\
0.05\end{array}$ & NR & $2.2(1.1-4.4)(\mathrm{LV}: \mathrm{HV})$ \\
\hline & & & & & Dissatisfied with TKA & NS & NR & $1.4(0.6-3.3)(\mathrm{LV}: \mathrm{HV})$ \\
\hline $\begin{array}{l}\text { Muilwijk et al } \\
(2007)\end{array}$ & 5 & - & 12 & - & Infection & $\begin{array}{l}\mathrm{p}< \\
0.05\end{array}$ & $4.9 \%$ vs $2.1 \%$ & $0.43(0.23-0.80)(\mathrm{HV}: \mathrm{LV})$ \\
\hline $\begin{array}{l}\text { Manley et al } \\
(2009)\end{array}$ & $1-12$ & $13-25$ & $26-50$ & $>50$ & $\begin{array}{l}\text { Early - mid term survivoship } \\
\text { (8 years) }\end{array}$ & NS & NR & $0.94(0.78-1.15)(\mathrm{LV}: \mathrm{HV})$ \\
\hline Ong et al (2009) & $1-12$ & $13-25$ & $26-50$ & $>50$ & Procedure duration & $\begin{array}{l}\mathrm{p}< \\
0.05\end{array}$ & $\begin{array}{l}165 \text { mins vs } 135 \\
\text { mins }\end{array}$ & NR \\
\hline \multirow[t]{2}{*}{$\begin{array}{l}\text { Yasunaga et al } \\
\text { (2009) }\end{array}$} & \multicolumn{4}{|c|}{$\begin{array}{l}\text { Used surgeon career volume of TKR } \\
\text { as surgeon volume variable: }<100, \\
100-499,>499\end{array}$} & Medical complication & NS & $7.7 \%$ vs $13.5 \%$ & $1.17(0.66-2.07)(\mathrm{HV}: \mathrm{LV})$ \\
\hline & & LOS & NS & $\begin{array}{l}38.9 \text { vs } 35 \\
\text { days }\end{array}$ & $N R$ & & & \\
\hline \multirow[t]{5}{*}{$\begin{array}{l}\text { Paterson et al } \\
\text { (2010) }\end{array}$} & $2-35$ & $36-50$ & $51-70$ & $>70$ & LOS & $\begin{array}{l}\mathrm{p}< \\
0.05\end{array}$ & NR & NR \\
\hline & & & & & MR & NS & $0.624 \%$ vs $0.547 \%$ & $1.02(0.63-1.67)(\mathrm{HV}: \mathrm{LV})$ \\
\hline & & & & & $\begin{array}{l}\text { Readmission for surgery } \\
(1 \mathrm{yr})\end{array}$ & NS & $0.594 \%$ vs $0.403 \%$ & $0.81(0.41-1.62)(\mathrm{HV}: \mathrm{LV})$ \\
\hline & & & & & Revision (1 yr) & NS & $1.279 \%$ vs $0.922 \%$ & $0.75(0.51-1.09)(\mathrm{HV}: \mathrm{LV})$ \\
\hline & & & & & Medical Complication & NS & $4.217 \%$ vs $4.553 \%$ & $0.90(0.67-1.19)(\mathrm{HV}: \mathrm{LV})$ \\
\hline \multirow[t]{2}{*}{ Wei et al (2010) } & $1-3$ & $4-9$ & $\begin{array}{l}10- \\
463\end{array}$ & - & LOS & $\begin{array}{l}\mathrm{p}< \\
0.05\end{array}$ & 10.79 vs 8.66 days & NR \\
\hline & & & & & Infection & $\begin{array}{l}\mathrm{p}< \\
0.05\end{array}$ & $0.99 \%$ vs $0.54 \%$ & 2.31 (1.379-3.876) (LV:HV) \\
\hline $\begin{array}{l}\text { Styron et al } \\
(2011)\end{array}$ & $1-17$ & $18-35$ & $36-66$ & $>67$ & LOS & $\begin{array}{l}\mathrm{p}< \\
0.05\end{array}$ & 4.14 vs 3.74 days & NR \\
\hline Baker et al (2011) & $1-52$ & & $>52$ & & Transfusion rate & $\begin{array}{l}\mathrm{p}< \\
0.05\end{array}$ & $13 \%$ vs $4 \%$ & NR \\
\hline
\end{tabular}

(LV Low volume, HV High or v. high volume, MR Mortality rate, LOS Length of stay, NS Not significant, NR Raw proportions not reported, PE Pulmonary embolus, DVT Deep venous thrombosis, MI Myocardial infarction, mins Time in minutes, WOMAC Western Ontario and McMaster Universities Osteoarthritis Index, * - see Table 3 for covariates adjusted for in adjusted odds ratios, \# - significant for trend, $95 \% \mathrm{Cl}=95 \%$ confidence intervals, $\mathrm{HV}: \mathrm{LV}=$ odds ratio expressed as high volume to low volume, LV:HV Odds ratio expressed as low volume to high volume, TKA Total knee arthroplasty). 
[25], urinary tract infection [26], upper gastrointestinal bleeding [26], and anemia [22].

Five studies examined length of stay $[21,25-27,32]$ and one study examined procedure length [28] (Table 1). Three studies examined 1-year, 3-year- and 8-year implant survivorship, respectively $[18,25,32]$, and one study examined patient-reported outcomes, including the Western Ontario and McMaster Universities Osteoarthritis Index (WOMAC), patient satisfaction, patientreported ability to flex 90 degrees, and patient-reported ability to fully extend [9] (Table 1).

Nine of 11 studies reported data on the measured outcomes using raw comparative proportions as well as adjusted odds ratios (OR) from multivariate logistic regression analyses adjusting for a variety of covariates. A summary of the study-specific covariates are presented in Table 3.

\section{Quality appraisal of studies}

All 11 studies were observational studies and are considered low quality studies as per GRADE system guidelines. None of the studies warranted an upgrade to moderate quality due to the relative small effect of surgeon volume on outcomes examined.

\section{Study results \\ Mortality rate (MR) (In hospital - 2 studies, 90 day - 3 studies)}

None of the studies identified a statistically significant relationship between surgeon volume and MR.

\section{Pulmonary embolism and deep venous thrombosis (2 studies)}

Among the 2 studies examining PE and/or DVT, neither reported a statistically significant association with surgeon volume.

\section{Surgical site infection (5 studies)}

Three of the 5 studies found a statistically significant association $(\mathrm{p}<0.05)$ between low surgeon volume and infection rates $[8,26,30]$. Wei et al found a higher inhospital infection rate among low volume (LV) surgeons $[0.99 \%$ (LV) vs. $0.54 \%$ high volume (HV) surgeon, adjusted OR: 2.31 (CI: 1.379 - 3.876)] [26] and Muilwijk et al found a lower infection rate 1 year post-TKA among HV surgeons [2.1\% (HV) vs $4.9 \%(\mathrm{LV})$, adjusted OR: 0.43 (CI: 0.23-0.80)] [30]. Neither study specified whether this was deep or superficial surgical site infection. Katz et al found decreased deep infections at 90 days post-TKA among HV surgeons $[0.29 \%(\mathrm{HV})$ vs. 0.55\% (LV), adjusted OR: 0.62 (CI: 0.37-1.06)], which was statistically significant for trend $(\mathrm{p}=0.006)$ [8]. Two studies did not find a significant association between surgeon volume and infection rate $[27,32]$.

\section{Medical complications (6 studies)}

Katz et al (2004) found a statistically significant decrease in pneumonia rates following TKA for HV surgeons [1.02\% (HV) vs. $1.68 \%(\mathrm{LV})$, adjusted OR 0.72 (CI 0.54 0.95)] [8]. Baker et al (2011) found a statistically significant decrease in transfusion rate following TKA for HV surgeons compared to LV surgeons (4\% vs $13 \%$ ). The

Table 3 Confounding variables controlled for in multivariate analysis in each study

\begin{tabular}{|c|c|}
\hline Study & Covariates controlled \\
\hline Kreder et al (2003) & age, comorbidity, gender, diagnosis, hospital procedure volume \\
\hline Katz et al (2004) & age, gender, comorbidity, Medicaid eligibility, diagnosis, hospital procedure volume \\
\hline Katz et al (2007) & age, gender, race, education, diagnosis, income, comorbidity, preoperative patient reported outcome (WOMAC) \\
\hline $\begin{array}{l}\text { Muilwijk et al } \\
(2007)\end{array}$ & ASA class \\
\hline $\begin{array}{l}\text { Manley et al } \\
(2009)\end{array}$ & age, gender, race, diagnosis, hospital procedure volume, hospital teaching status, hospital ownership, hospital region, income \\
\hline $\begin{array}{l}\text { Manley et al } \\
(2009)\end{array}$ & age, gender, race, diagnosis, hospital procedure volume, hospital teaching status, hospital ownership, hospital region, income \\
\hline Ong et al (2009) & $\begin{array}{l}\text { age, gender, comorbidity, race, diagnosis, Medicare eligibility, hospital teaching status, hospital ownership, hospital location, } \\
\text { hospital size, hospital procedure volume }\end{array}$ \\
\hline $\begin{array}{l}\text { Yasunaga et al } \\
(2009)\end{array}$ & age, gender, BMl, diagnosis, comorbidity, hospital procedure volume \\
\hline $\begin{array}{l}\text { Paterson et al } \\
(2010)\end{array}$ & age, gender, comorbidity, diagnosis, hospital teaching status, hospital procedure volume \\
\hline Wei et al (2010) & age, gender, diagnosis, comorbidity, hospital ownership, hospital region \\
\hline Styron et al (2011) & $\begin{array}{l}\text { age, gender, race, comorbidity, income, insurance status, geographic region, hospital region, hospital teaching status, hospital } \\
\text { ownership, hospital size, hospital procedure volume }\end{array}$ \\
\hline Baker et al (2011) & age, surgeon volume, preoperative hemoglobin, gender, type of anaesthetic, ASA, surgeon experience, indication \\
\hline
\end{tabular}

(ASA American Society of Anesthesiologists, BMI Body mass index, WOMAC Western Ontario and McMaster Universities Osteoarthritis Index). 
remaining 4 studies did not report a statistically significant association between surgeon volume and postoperative medical complications [25-27,32] (Table 2).

\section{Length of stay (5 studies)}

Four studies reported a significant increase in LOS among patients of LV surgeons [21,25,32,45]. Yasunaga et al did not find a significant association between LOS and surgeon volume [27]. Numerical data for LOS were not uniformly reported across studies and are summarized in Table 2.

\section{Procedure length (one study)}

Ong et al found a significant increase in TKA procedure time for LV surgeons (165 min vs $135 \mathrm{~min}$ ) [28].

\section{Implant survivorship (3 studies)}

Manley et al (2009) did not find a significant association between 8-year implant survivorship and surgeon volume [18]. Similarly, Kreder et al (2003) and Paterson et al (2010) did not find a significant association between surgeon volume and 3-year and 1-year revision rate, respectively [25,32] (Table 2).

\section{Patient-reported outcomes (one study)}

Patients of LV surgeons had significantly lower (i.e. worse) WOMAC scores [76 (LV) vs. 83 (HV)], and were more likely to have a WOMAC score of $<60[22.6 \%$ (LV) vs. 8.4\% (HV), adjusted OR 2.1 (CI 1.1 - 4.2)], two years post TKA [9]. In addition, patients of LV surgeons were more likely to report an inability to flex the knee to 90 degrees (adjusted OR 2.9, CI 1.6 - 5.5), and more likely to report an inability to achieve full extension at 2 years post operation (adjusted OR 2.2, CI 1.1 - 4.4) [9] (Table 2).

\section{Discussion}

Understanding the relationship between provider volume and outcomes for TKA is critical to informing discussions concerning 'centralization' or 'regionalization' [24] and overall efforts to improve quality and outcomes of care in TKA. The principle behind centralization or regionalization is that improved patient outcomes can be achieved by concentrating complex surgical procedures in regional centers, or "centers of excellence". Several studies have demonstrated a relationship between higher provider volumes and improved outcomes for surgical procedures such as coronary artery bypass grafting, aortic aneurysm repair, carotid endarterectomy, and complex gastrointestinal surgeries [46]. Two principal hypotheses have been put forward to explain these observations: (1) physicians and hospitals develop more effective skills as they treat more patients ("practice makes perfect') and (2) physicians and hospitals reporting better outcomes receive more referrals and thus accrue larger volumes ('selective referral') [14,46]. If these hypotheses are broadly applicable, our expectation was that similar positive associations between higher surgeon volume and improved patient outcomes would be observed in TKA.

Our review of the limited literature in primary TKA revealed significant variability across studies in the categorization of surgeon procedure volumes. This variability rendered comparisons of study findings challenging, and highlighted a critical need for consistency in future research. Despite these challenges, we report a general trend of improved outcomes among 'higher' volume surgeons although we are careful to note that statistical significance was not achieved across all studies or outcomes. After reviewing the available studies, we would identify a high surgeon volume as > 50 TKA per year. Three studies identified a statistically significant relationship between low surgeon volume and higher infection rates $(0.26 \%-2.8 \%$ higher $)$. While the magnitude of the reported differences in infection rates were relatively small, when considered in the context of the expected 3.5 million TKA procedures to be performed over the next 20 years in the US alone, this may represent a significant outcome at a population level.

The majority of studies examining LOS found a statistically significant increase in LOS for LV surgeons. Evidence on process of care adherence (such as use of antibiotic prophylaxis, DVT prophylaxis, beta-blocker use in high risk patients) has demonstrated that adherence to evidence-based processes of care improves quality of care and decreases LOS in total joint replacement surgery [23]. Bozic et al found a weak negative correlation between surgeon volume and number of missed evidence based processes of care [23]. It is possible that adherence to evidence based processes of care may account for some of the decreases in LOS for HV surgeons. Similarly, utilization of clinical care pathways for patients undergoing total joint arthroplasty have also demonstrated improved quality of care and shorter LOS [47-49]. It is not known however, if LV surgeons are less likely to utilize a clinical care pathway. Further study in the relationship between surgeon volume, clinical care pathways and process of care measures may be useful in understanding why LV surgeons have longer LOS.

Early to midterm (up to 8 years) implant survivorship did not appear to be influenced by surgeon volume $[18,25,32]$. Whether similar findings hold over the longer-term (i.e. $>8$ years) is unknown. Further long term survivorship studies would be useful in understanding the relationship between surgeon volume and implant survivorship.

In the one study which examined patient-reported outcomes, Katz et al (2007) reported a positive association 
between LV surgeons and poorer TKA outcomes [9]. However, the lack of additional studies examining patient-reported outcomes precludes any general statement concerning the influence of surgeon volume on these outcomes. It also highlights an important need for further work in this area to critically inform relevant policy discussions and decisions concerning TKA.

Studies examining hospital volume and TKA outcomes have demonstrated decreased mortality, infection and pulmonary embolism [8,10,16,32,39]. Furthermore, two studies have demonstrated decreased TKA survivorship for low volume hospitals [18,32]. Given these findings, hospital volume appears to have more impact on outcome for TKA than surgeon volume, however the quality and limitations of these studies prevents the delivery of definitive or 'strong' recommendations at this point [20]. Further studies will be important in determining the relative importance of surgeon volume and hospital volume to TKA outcome.

In 2002, Halm et al performed a review of the literature on volume-related outcomes in health care, and included a wide variety of surgical procedures [14]. They identified one study that examined the influence of hospital volume on TKA outcomes. In 2007, Shervin et al performed a review of orthopedic procedures, examining the association between hospital and surgeon volume, and outcomes [50]. In their review, they included 4 studies examining TKA outcomes and surgeon volume which are also included in this review. Finally, 2 recent reviews by Marlow et al and Critchely et al, examined surgeon volume and outcomes in TKA procedures. Both reviewed primary and revision knee arthroplasty procedures [24,51]. Marlow et al included 3 studies that examined surgeon volume and primary TKA outcomes [24]. Critchley et al presented data on primary hip and knee arthroplasty procedures together [51]. The present review differs from and expands on the prior reviews in that the present focus was on primary TKA outcomes alone, and the association with surgeon volume. Furthermore, we included several recently published studies not included in previous reviews.

Due to the nature of the literature from which this review was derived, there are study limitations. Studies on surgeon volume are primarily retrospective in nature and based on national health care databases and surveys which are limited in the number of variables collected. Furthermore, different health care databases capture different patient groups making comparisons challenging. Medicare data in the US contains data on patients over 65 , which is different from other national health care databases such as OHIP. As with all non-randomized studies, there is potential for uncontrolled confounding factors which can bias the results. Additionally, the studies reviewed were variable in methodology, with variable thresholds for surgeon volume categorization. Similarly, studies were highly variable in outcomes measured (i.e. superficial vs. deep infection), and timing of measured outcomes (i.e. in-hospital vs. 90 day MR). The variability across the key variable of surgeon volume precluded formal meta-analysis from being performed.

While our findings suggest a trend towards better outcomes for higher volume surgeons, we do not believe there is sufficient evidence to fully support initiatives to concentrate procedures within specific regions or centres on the basis of surgeon volume alone. All of the available studies are of 'low quality' as per GRADE system, making any clinical recommendations challenging. In addition, it is unclear if this general trend of improved outcomes for higher volume surgeons warrants regionalization to higher volume surgeons. Studies examining the effect of regionalization of TKA to high volume hospitals provide some evidence that regionalization may not be the solution [35,52]. Evidence suggests that some patients would refuse to have surgery in an unfamiliar setting, preferring to attend a local health provider with lower procedure volume $[35,52]$. In the US, the poor, less educated, elderly, as well as racial/ethnic minorities are more likely to undergo TKA at low volume centers [11,36,38]. Regionalization of TKA to high volume centres and surgeons may further exacerbate existing disparities in the utilization of TKA and restrict access to some patients who would otherwise use a low volume provider for TKA, increasing the number of patients who decline or defer their elective TKA surgery with resultant poorer health outcomes $[2,11,53]$. A regionalization program involving referral to high volume surgeons and hospitals might decrease the already low rate of perioperative complications at the cost of increasing arthritis related disability [11]. Evidence suggests that having TKA in low volume hospitals costs more and produces worse outcomes than having TKA in high volume centers, but having TKA in low volume centers is still more cost effective than not having TKA at all [35]. While these studies were specific to examining the role of hospital volume on cost effectiveness of TKA, it is possible that the same may hold true for surgeon volume and TKA. Further study into the cost effectiveness of regionalization will be paramount before a universal referral program designed to shift patients to high volume surgeons becomes policy. Cost utilization and effectiveness will be crucial as healthcare resources become more scarce, with the principle of providing optimum patient care in the most efficient manner the ultimate goal.

\section{Conclusions}

There is a general trend towards better outcomes for higher volume surgeons, however it is unclear if this trend warrants widespread adoption of regionalization policies. The evidence that is available is of 'low quality' 
and the strength of recommendations from the available evidence is weak. Further study is needed before regionalization policies are adopted.

\section{Abbreviations \\ TKA: Total knee arthroplasty; THA: Total hip arthroplasty; N: Sample size; US: United States; HCUP-NIS: Health Care Cost and Utilization Project Nationwide Inpatient Sample; OHIP: Ontario Health Insurance Plan; CIHI: Canadian Institute for Health Information; NHI: National Health Insurance; PREZIES: Preventie Ziekenhuisinfecties door Surveillance Network database; MR: Mortality rate; PE: Pulmonary embolism; DVT: Deep venous thrombosis; WOMAC: Western Ontario and McMaster Universities Osteoarthritis index; LOS: Length of stay; OR: Odds ratio; LV: Low volume; HV: High volume.}

\section{Competing interests}

The authors declare that they have no competing interests.

\section{Authors' contributions}

RLL: Literature search and abstract review. Data abstraction and data analysis. Manuscript drafting, approval of the final manuscript. AVP: Statistical analysis, critical manuscript review and editing, approval of the final manuscript. RG: Data abstraction and analysis, manuscript writing, approval of the final manuscript. NNM: Initial study conception, manuscript editing, approval of the final manuscript.

\section{Author details}

'Division of Orthopaedics, Department of Surgery Kingston General Hospital, Queen's University, 76 Stuart St., Nickle 3, Rm 9-309, Kingston, ON K7L 2V7, Canada. ${ }^{2}$ Division of Orthopaedic Surgery and The Arthritis Program Toronto Western Hospital, University Health Network Institute of Health Policy, Management and Evaluation, University of Toronto, 399 Bathurst St., EW 1-427, Toronto, ON M5T 2S8, Canada. ${ }^{3}$ Division of Orthopaedics, Department of Surgery Toronto Western Hospital, University Health Network, University of Toronto, 399 Bathurst St., EW 1-439, Toronto, ON M5T 2S8, Canada.

Received: 5 August 2012 Accepted: 6 December 2012 Published: 14 December 2012

\section{References}

1. Ritter MA, Albohm MJ, Keating EM, Faris PM, Meding JB: Comparative outcomes of total joint arthroplasty. J Arthroplasty 1995, 10:737-741.

2. Fortin PR, Clarke AE, Joseph L, Liang MH, Tanzer M, Ferland D, Phillips C, Partridge AJ, Bélisle P, Fossel AH, Mahomed N, Sledge CB, Katz JN: Outcomes of total hip and knee replacement: preoperative functional status predicts outcomes at six months after surgery. Arthritis Rheum 1999, 42:1722-1728.

3. Callahan CM, Drake BG, Heck DA, Dittus RS: Patient outcomes following tricompartmental total knee replacement. A meta-analysis. JAMA 1994, 271:1349-1357.

4. Kurtz S, Ong K, Lau E, Mowat F, Halpern M: Projections of primary and revision hip and knee arthroplasty in the United States from 2005 to 2030. J Bone Joint Surg Am 2007, 89:780-785.

5. Bourne RB, McCalden RW, MacDonald SJ, Mokete L, Guerin J: Influence of patient factors on TKA outcomes at 5 to 11 years followup. Clin Orthop Relat Res 2007, 464:27-31.

6. Rolfson O, Dahlberg LE, Nilsson J-A, Malchau H, Garellick G: Variables determining outcome in total hip replacement surgery. J Bone Joint Surg Br 2009, 91:157-161.

7. Barrack RL, Schrader T, Bertot AJ, Wolfe MW, Myers L: Component rotation and anterior knee pain after total knee arthroplasty. Clin Orthop Relat Res 2001, 392:46-55.

8. Katz JN, Barrett J, Mahomed NN, Baron JA, Wright RJ, Losina E: Association between hospital and surgeon procedure volume and the outcomes of total knee replacement. J Bone Joint Surg Am 2004, 86-A:1909-1916.

9. Katz JN, Mahomed NN, Baron JA, Barrett JA, Fossel AH, Creel AH, Wright J, Wright EA, Losina E: Association of hospital and surgeon procedure volume with patient-centered outcomes of total knee replacement in a population-based cohort of patients age 65 years and older. Arthritis Rheum 2007, 56:568-574.
10. Hervey SL, Purves HR, Guller U, Toth AP, Vail TP, Pietrobon R: Provider Volume of Total Knee Arthroplasties and Patient Outcomes in the HCUP-Nationwide Inpatient Sample. J Bone Joint Surg Am 2003, 85-A:1775-1783.

11. Losina E, Kessler CL, Wright EA, Creel AH, Barrett JA, Fossel AH, Katz JN: Geographic diversity of low-volume hospitals in total knee replacement: implications for regionalization policies. Medical care 2006, 44:637-645.

12. Begg CB, Cramer LD, Hoskins WJ, Brennan MF: Impact of hospital volume on operative mortality for major cancer surgery. JAMA 1998, 280:1747-1751.

13. Farley DE, Ozminkowski RJ: Volume-outcome relationships and in-hospital mortality: the effect of changes in volume over time. Medical care 1992, 30:77-94.

14. Halm EA, Lee C, Chassin MR: Is volume related to outcome in health care? A systematic review and methodologic critique of the literature. Ann Intern Med 2002, 137:511-520.

15. Singh JA, Kwoh CK, Boudreau RM, Lee G-C, Ibrahim SA: Hospital volume and surgical outcomes after elective hip/knee arthroplasty: a risk-adjusted analysis of a large regional database. Arthritis Rheum 2011, 63:2531-2539.

16. SooHoo NF, Zingmond DS, Lieberman JR, Ko CY: Primary total knee arthroplasty in California 1991 to 2001: does hospital volume affect outcomes? J Arthroplasty 2006, 21:199-205.

17. Norton EC, Garfinkel SA, McQuay L, Heck DA, Wright JG, Dittus R, Lubitz RM: The effect of hospital volume on the in-hospital complication rate in knee replacement patients. Health Serv Res 1998, 33:1191-1210

18. Manley M, Ong K, Lau E, Kurtz SM: Total knee arthroplasty survivorship in the United States Medicare population: effect of hospital and surgeon procedure volume. J Arthroplasty 2009, 24:1061-1067.

19. Moher D, Liberati A, Tetzlaff J, Altman DG, PRISMA Group: Preferred reporting items for systematic reviews and meta-analyses: the PRISMA statement. BMJ 2009, 339:b2535.

20. Guyatt GH, Oxman AD, Vist GE, Kunz R, Falck-Ytter Y, Alonso-Coello P, Schünemann HJ, GRADE Working Group: GRADE: an emerging consensus on rating quality of evidence and strength of recommendations. BMJ 2008, 336:924-926.

21. Styron JF, Koroukian SM, Klika AK, Barsoum WK: Patient vs Provider Characteristics Impacting Hospital Lengths of Stay After Total Knee or Hip Arthroplasty. J Arthroplasty 2011, 26:1418-1426. e2.

22. Baker P, Dowen D, McMurtry I: The effect of surgeon volume on the need for transfusion following primary unilateral hip and knee arthroplasty. Surgeon 2011, 9:13-17.

23. Bozic KJ, Maselli J, Pekow PS, Lindenauer PK, Vail TP, Auerbach AD: The influence of procedure volumes and standardization of care on quality and efficiency in total joint replacement surgery. The Journal of Bone and Joint Surgery 2010, 92:2643-2652.

24. Marlow NE, Barraclough B, Collier NA, Dickinson IC, Fawcett J, Graham JC, Maddern GJ: Centralization and the relationship between volume and outcome in knee arthroplasty procedures. ANZ journal of surgery 2010, 80:234-241.

25. Paterson JM, Williams Jl, Kreder HJ, Mahomed NN, Gunraj N, Wang X, Laupacis A: Provider volumes and early outcomes of primary total joint replacement in Ontario. Can J Surg 2010, 53:175-183.

26. Wei M-H, Lin Y-L, Shi H-Y, Chiu H-C: Effects of provider patient volume and comorbidity on clinical and economic outcomes for total knee arthroplasty: a population-based study. J Arthroplasty 2010, 25:906-912. e1.

27. Yasunaga $H$, Tsuchiya $K$, Matsuyama $Y$, Ohe $K$ : Analysis of factors affecting operating time, postoperative complications, and length of stay for total knee arthroplasty: nationwide web-based survey. J Orthop Sci 2009, 14:10-16.

28. Ong K, Lau E, Manley M, Kurtz SM: Patient, hospital, and procedure characteristics influencing total hip and knee arthroplasty procedure duration. J Arthroplasty 2009, 24:925-931.

29. Schroer WC, Calvert GT, Diesfeld PJ, Reedy ME, LeMarr AR: Effects of increased surgical volume on total knee arthroplasty complications. J Arthroplasty 2008, 23:61-67.

30. Muilwijk J, van den Hof S, Wille JC: Associations between surgical site infection risk and hospital operation volume and surgeon operation 
volume among hospitals in the Dutch nosocomial infection surveillance network. Infect Control Hosp Epidemiol 2007, 28:557-563.

31. Nunley RM, Lachiewicz PF: Mortality after total hip and knee arthroplasty in a medium-volume university practice. J Arthroplasty 2003, 18:278-285

32. Kreder HJ, Grosso P, Williams II, Jaglal S, Axcell T, Wal EK, Stephen DJG: Provider volume and other predictors of outcome after total knee arthroplasty: a population study in Ontario. Can I Surg 2003, 46:15-22.

33. Mahaluxmivala J, Bankes MJ, Nicolai P, Aldam CH, Allen PW: The effect of surgeon experience on component positioning in 673 Press Fit Condylar posterior cruciate-sacrificing total knee arthroplasties. J Arthroplasty 2001, 16:635-640.

34. Lavernia CJ, Guzman JF: Relationship of surgical volume to short-term mortality, morbidity, and hospital charges in arthroplasty. J Arthroplasty 1995, 10:133-140.

35. Losina E, Walensky RP, Kessler CL, Emrani PS, Reichmann WM, Wright EA, Holt HL, Solomon DH, Yelin E, Paltiel AD, Katz JN: Cost-effectiveness of total knee arthroplasty in the United States: patient risk and hospital volume. Arch Intern Med 2009, 169:1113-1121. discussion 1121-2.

36. Losina E, Wright EA, Kessler CL, Barrett JA, Fossel AH, Creel AH, Mahomed NN, Baron JA, Katz JN: Neighborhoods matter: use of hospitals with worse outcomes following total knee replacement by patients from vulnerable populations. Arch Intern Med 2007, 167:182-187.

37. Mitsuyasu S, Hagihara A, Horiguchi H, Nobutomo K: Relationship between total arthroplasty case volume and patient outcome in an acute care payment system in Japan. J Arthroplasty 2006, 21:656-663.

38. SooHoo NF, Zingmond DS, Ko CY: Disparities in the utilization of high-volume hospitals for total knee replacement. J Natl Med Assoc 2008, 100:559-564.

39. SooHoo NF, Lieberman JR, Ko CY, Zingmond DS: Factors predicting complication rates following total knee replacement. J Bone Joint Surg Am 2006, 88:480-485.

40. Ohmann C, Verde PE, Blum K, Fischer B, de Cruppé W, Geraedts M: Two short-term outcomes after instituting a national regulation regarding minimum procedural volumes for total knee replacement. The Journal of Bone and Joint Surgery 2010, 92:629-638.

41. Hagen TP, Vaughan-Sarrazin MS, Cram P: Relation between hospital orthopaedic specialisation and outcomes in patients aged 65 and older: retrospective analysis of US Medicare data. BMJ 2010, 340:c165.

42. Judge A, Chard J, Learmonth I, Dieppe P: The effects of surgical volumes and training centre status on outcomes following total joint replacement: analysis of the Hospital Episode Statistics for England. J Public Health (Oxf) 2006, 28:116-124.

43. Cram P, Vaughan-Sarrazin MS, Wolf B, Katz JN, Rosenthal GE: A comparison of total hip and knee replacement in specialty and general hospitals. J Bone Joint Surg Am 2007, 89:1675-1684.

44. Katz JN, Bierbaum BE, Losina E: Case mix and outcomes of total knee replacement in orthopaedic specialty hospitals. Medical care 2008 46:476-480.

45. Garcia RM, Messerschmitt PJ, Furey CG, Bohlman HH, Cassinelli EH: Weight Loss in Overweight and Obese Patients Following Successful Lumbar Decompression. The Journal of Bone and Joint Surgery 2008, 90:742-747.

46. Luft HS, Hunt SS, Maerki SC: The volume-outcome relationship: practice-makes-perfect or selective-referral patterns? Health Serv Res 1987 22:157-182.

47. Barbieri A, Vanhaecht K, Van Herck P, Sermeus W, Faggiano F, Marchisio S, Panella M: Effects of clinical pathways in the joint replacement: a meta-analysis. BMC Med 2009, 7:32.

48. Pennington JM, Jones DPG, Mclntyre S: Clinical pathways in total knee arthroplasty: a New Zealand experience. Journal of orthopaedic surgery (Hong Kong) 2003, 11:166-173.

49. Ho DM, Huo MH: Are critical pathways and implant standardization programs effective in reducing costs in total knee replacement operations? J. Am. Coll. Surg. 2007, 205:97-100.

50. Shervin N, Rubash HE, Katz JN: Orthopaedic procedure volume and patient outcomes: a systematic literature review. Clin Orthop Relat Res 2007, 457:35-41.

51. Critchley RJ, Baker PN, Deehan DJ: Does surgical volume affect outcome after primary and revision knee arthroplasty? A systematic review of the literature. The Knee 2012, 19:513-518.
52. Finlayson SR, Birkmeyer JD, Tosteson AN, Nease RF: Patient preferences for location of care: implications for regionalization. Medical care 1999, 37:204-209

53. Baron JA, Barrett J, Katz JN, Liang MH: Total hip arthroplasty: use and select complications in the US Medicare population. Am J Public Health 1996, 86:70-72.

doi:10.1186/1471-2474-13-250

Cite this article as: Lau et al:: The role of surgeon volume on patient outcome in total knee arthroplasty: a systematic review of the literature. BMC Musculoskeletal Disorders 2012 13:250.

\section{Submit your next manuscript to BioMed Central and take full advantage of:}

- Convenient online submission

- Thorough peer review

- No space constraints or color figure charges

- Immediate publication on acceptance

- Inclusion in PubMed, CAS, Scopus and Google Scholar

- Research which is freely available for redistribution 